\title{
Defence Policy under the Labour Government: Operational Dynamism and Strategic Inertia
}

\section{Introduction}

This paper examines and explains the process and outcome of defence reform during the Labour Government (1997-2010). It argues that the experiences of military operations combined with observation of the successes and failures of concepts and capabilities associated with the 'Revolution in Military Affairs' (RMA) ${ }^{1}$ led, by the mid-2000s, to the identification of a model of military 'best practice' relevant to short to medium-term conflict scenarios. This model has taken the form of a joint, network-enabled military endowed with the 'balance' allowing it to participate in operations across the full-spectrum of intensity. The paper finds that defence reform at the operational level has been dynamic and guided by the dictates of military 'best practice', rather than the path dependency, organisational culture or transnational norms of conventional warfare (Farrell, 2001; 2005). This finding contrasts markedly with the arguments of Cornish and Dorman (2009a: 261) who posit that British defence policy, planning and analysis 'has reached a state of organisational, bureaucratic and intellectual decay'.

Nevertheless, the paper highlights significant deficiencies at the strategic-level of defence planning. It finds that the capacity of the British military to translate the experiences of military operations in into changes to force postures and defence capability acquisition has been circumscribed by the presence of organisational politics between the Single-Services which, in competing for budget share, have fostered an 'overheating' of the UK equipment programme and stagnation in force planning. Yet the impact of organisational politics is not a stand-alone variable. It derives, instead, from the reduced capacity of the core executive to make far-reaching changes to the content and process of defence capability acquisition and to force structures. Causality lies in the electoral cycle that, during the final term of the Labour government (2005-10) has reduced the autonomy of the core executive in defence policy and has incentivised the short-term temporal management of convergence with the imperatives of the international security environment. Neoclassical Realism, that recognises the independent role of 'international structure' in driving military emulation, but that emphasises the intervening role of domestic variables in slowing down the transmission belt linking changes in the international security environment to policy response, emerges as the most convincing framework to conceptualise the process of British defence reform.

The study makes an important contribution to the contemporary literature on British defence reform and to theoretical debates on the sources of military change. The articles of Cornish and Dorman (2009a; 2009b; 2010), Edmunds, (2010) and Farrell and Gordon (2009) provide vital empirical insights into the process of recent UK defence reforms. These studies fail, however, to properly extrapolate the theoretical implications of the process and outcome of British military transformation. Cornish and Dorman (2010: 409) correctly note that the 'prolonged hiatus in grand strategic policy and planning has been extremely unhelpful' and decry the lack of a clear sense of political purpose underpinning UK defence policy, identifying deficiencies in declaratory policy, military strategy and the defence budget (2009a: 248). Yet they do not fully explain the root causes of the combination of dynamism and inertia at the operational and strategic levels of defence policy during the Labour Government. Furthermore, the theoretically-informed work on British defence policy (Farrell, 2008) adopts a cultural approach.

This paper forms part of a broader wave of recent scholarship that attempts to reassert the analytical leverage of Realist theory in conceptualising defence and security policy in post-

\footnotetext{
${ }^{1}$ For a definition of the RMA and its associated concepts, please see page 2.
} 
Cold War Europe (Dyson, 2008; 2010, Hyde-Price, 2007; Posen, 2006; Rynning, 2001/02) and raises some interesting implications for theories of defence transformation. The paper also makes an important empirical contribution by exploring the neglected area of the management of military input to British defence planning at the operational and strategic levels.

The paper begins by mapping the UK's selective emulation of the RMA. After outlining Cultural and Neorealist approaches to defence reform, the paper tests these approaches against the process of British military transformation at operational level and examines the structuring of military input to defence planning. The paper then turns to the process of reform at the strategic level, highlighting the analytical leverage of Neoclassical Realism and proceeds by examining the organisational reforms which will be undertaken to provide 'institutional protection' for the process and implementation of the 2010 Strategic Defence and Security Review (SDSR). The paper concludes by outlining the implications of the study for future empirical and theoretical research.

\section{Defence Reform under Labour: A Selective Emulation of the RMA}

Until the post-2005 focus on the capabilities and doctrines suitable for irregular warfare, the RMA formed the central organising principle underpinning US defence reform. The RMA is succinctly defined by Krepinevic (2004: 30): 'It is what occurs when the application of new technologies into a significant number of military systems combines with innovative operational concepts and organisational adaptation in a way that fundamentally alters the character and conduct of conflict.' The RMA has coalesced around three features. Firstly, expeditionary forces characterised by joint command structures. Secondly, Network-Centric Warfare (NCW): a shift from weapons platforms to knowledge-empowered networked forces capable of exercising agility and precision in applying attritional force (Dahl, 2002: 5). Effects-Based Operations (EBO) have dominated conceptual development on NCW and formed, until 2006, the third key feature of transformation. EBO focus on the conduct of rapid, decisive operations against near-peer competitors, involving close networked coordination and the mobilisation of all sources of national power (political, economic, military and diplomatic) (Ho, 2005: 172-74). British Defence Reform has involved an emulation of the concepts and capabilities associated with the RMA. This section will, however, highlight the selective nature of this emulation that is marked by several distinctive features. These include scepticism of the utility of technology, a preference for decentralised command and control and a focus on developing the capacity to participate in conflict that can vary quickly in intensity.

It was not until the Labour Government's election in 1997 that far-reaching change took place to the objectives and instruments of policy. The 1997/98 Strategic Defence Review (SDR) outlined a wide range of defence missions and created a new role: 'defence diplomacy'2. In place of Territorial and Alliance Defence, the SDR set out a new expeditionary strategy of 'forward defence': that it is 'better to meet a crisis than to wait for it to come to you' (Dorman, 2006: 154). The Review also undertook structural reform, reorganising the military to permit two small-scale deployments or one full-scale deployment and in recognition of the increasing importance of 'jointness', created the Joint Rapid Reaction Force, structured around Navy, Air and Infantry assets (King, 2005: 325). In short, the SDR represented an important shift to strategic mobility and deployment outside of Europe in support of crisis-management. While these changes began under the Conservatives, as McInnes (1998: 836) notes: 'Labour has pushed them further than before, and decisively so'.

The 2002 'New Chapter' formed an initial recognition of the urgency of adapting to the RMA and, following $9 / 11$, signaled an important change in the focus of strategy from North

\footnotetext{
2 McInnes (1998: 836-7) defines Defence Diplomacy as 'activities falling short of military operations designed to prevent or diffuse crises'.
} 
Africa/the Middle East to global power projection (Dorman, 2006: 154-5). The 2003 and 2004 Defence White Papers (DWPs) outlined the implications of post-Cold War experiences more clearly in terms of capabilities and conceptual/doctrinal development. The 2004 DWP also altered force structures to ensure the capacity to concurrently conduct (as part of a coalition) three small and medium-scale operations or simultaneously conduct one large scale and one small-scale operation. ${ }^{3}$

The Air Force adapted to the requirements of expeditionary operations by placing a stronger emphasis on developing the Typhoon's ground attack capabilities and by acquiring the Joint Combat Aircraft (Farrell, 2008: 799). Furthermore, in June 2006 the Expeditionary Air Wings were established at the RAF's main operating bases to improve the deployability of the air components of force packages. Beginning with the publication of the first edition of British Maritime Doctrine in 1996, the Navy underwent a doctrinal shift from sea control/anti-submarine warfare to maritime force projection. Capability procurement has augmented the Navy's expeditionary capacity, including two aircraft carriers (Future Carriers, (CVF)) capable of deploying 40 aircraft (compared to the 22 aircraft of the existing carriers) ready for service in 2016 and 2018; the deployment of six anti-air warfare Type-45 destroyers by 2009 and six Astute Class Submarines, the first of which entered into service in 2009 (Farrell, 2008: 799).

The 2003/04 DWPs outlined a more focused reform of the Army, including developing increasingly deployable brigades: two heavy-armoured brigades, three Medium-Weight Brigades, one Light-Brigade, the Air-Assault and Royal Marine Commando Brigades (Farrell, 2008: 800). ${ }^{4}$ These developments were complemented by the Joint Medium-Weight Capability Analytical Concept for Military Operations, designed to provide 'strategic reach', 'operational and tactical agility', 'sustainability' and 'endurance' (Farrell, 2008: 801). The 2008 Future Land Operational Concept (FLOC) outlines the goal of creating a 'balanced' Army that, by 2018, will be able to participate in conflict of rapidly varying intensity (Stabilisation and COIN operations) as well as classic Major Combat Operations (MCO). ${ }^{5}$

The 2002 'New Chapter' and 2003 DWP involved an explicit, though selective, emulation of US military 'transformation'. The 2003 DWP reinforced the SDR's emphasis on jointness, signaled a shift from platform-centric planning to a Networked-Enabled Capability $(\mathrm{NEC})^{6}$ and heralded an Effects-Based Approach to Operations (EBAO) (Benbow: 2009: 24). British NEC (that will reach a 'mature' state between 2020-30 characterised by synchronisation between joint military forces) forms a moderate emulation of NCW (Farrell, 2008: 787-8; Mandille, 2003: 50-1). ${ }^{7}$ NEC seeks to exploit the tactical and operational advantages delivered by technology, but is more circumspect about networking's potential to transform the nature of warfare (Dorman, 2006: 156; Farrell, 2008: 786-7).

Initiated in 2003, British EBO initially adopted a scientific approach to forecasting effects (Boyce, 2003: 30-7; Farrell, 2008: 790-3). ${ }^{8}$ However, in 2005 EBO was replaced by EBAO, reflecting the recognition that it was not military operations themselves which had changed in character, but the approach to operations (Farrell, 2008: 793). EBAO emphasises not only operational end-states envisaging 'defeat of the enemy', but also the creation of 'prosperity', 'security', 'reliable infrastructure' and 'governance' (Farrell, 2008: 794). As the 2008 British Defence Doctrine notes: 'the UK needs to maintain the ability to respond swiftly and

\footnotetext{
3 'Delivering Security in a Changing World: Future Capabilities', 2004, pt.1.2.

4 'Future Capabilities', 2004, pts.2.11-2.18; Delivering Security in a Changing World: Defence White Paper', 2003, pt.4.12.

5 'FLOC', 2008, pt.111.

6 'Defence White Paper', 2003, pt.1.5.

7 'Future Capabilities', 2004, pts.2.1-2.3. See also 'Network Enabled Capability', JSP 777, edn. 1, MoD, p.10.

8 Interviews, DCDC, Shrivenham, 18 November 2009.
} 
decisively across the full range of intervention scenarios.' 9 The concept of EBAO has, therefore, been located within a multi-agency approach to operations ensuring that civilian agencies take the lead when appropriate. This has come to be termed the 'Comprehensive Approach' 10 that seeks to integrate the diplomatic, military, economic and informational dimensions of operations (Benbow, 2009: 29; Dorman, 2007: 312; Farrell, 2008: 793). EBAO is conceived of as an approach that, embedded within the Comprehensive Approach, can facilitate the integration of all government agencies in delivering both kinetic and non-kinetic effects. ${ }^{11}$

EBAO also integrates the negative experiences of the US with the hierarchical 'longscrewdriver approach' to military command (Storr, 2003: 123). The British system of Mission Command remains dominant. (Dorman, 2006: 155; Storr, 2003: 119-21). Rooted in the concept of the 'Corps d'Armee' of the Napoleonic Wars and Prussian military thought, the practice of Mission Command was formally adopted by the British Army in 1987 in doctrinal reforms initiated by General Sir Nigel Bagnall, the former Chief of the General Staff (1985-87). Mission Command involves ensuring that the military commander is clear on an operation's political goals and that these goals are effectively communicated to lower-levels of command, which are permitted a significant level of freedom to display initiative. ${ }^{12}$ Mission Command enables a balance between 'direction and delegation'13 allowing agility in operations of rapidly-varying intensity (Farrell, 2008: 788; Milton, 2001: 41-4; Storr, 2003: 123). Mission Command forms a key pillar of the 'Manoeuvrist Approach'14 to operations that is characterised by 'momentum, tempo and agility, which in combination, aim to achieve shock and surprise' thereby 'shattering the enemy's overall cohesion and will to fight, rather than his material' and delivering the capability to attain effects disproportionately higher than the level of force applied. ${ }^{15} \mathrm{NEC}$ is viewed as a means to strengthen the Manoeuvrist Approach and enhance the military's capacity to conduct MCO and 'Stabilisation/COIN' (Benbow: 2009: 29). ${ }^{16}$

Defence reform has, therefore, focused not only on high-technology assets, but has also invested in 'human factors' to strike a balance between the 'warrior ethos' and the skills necessary for lower-intensity tasks and to equip field commanders with the ability to undertake decentralised decision-making within a complex operational environment (Kiszely, 2006: 1920). ${ }^{17}$ The need to further develop cultural skills is also recognised by the October 2008 FLOC that emphasises the importance of training delivering an 'adaptive foundation'. ${ }^{18}$ The centrality of cultural awareness to land forces is most clearly evidenced by the January 2009 Joint Doctrine Note 1/09: 'The Significance of Culture to the Military'. The document outlines a shift away from a rank/command-determined level of cultural capability training to a task-specific structure for determining levels of cultural-generic and cultural-specific education. ${ }^{19}$ These changes represent important developments in UK Defence Doctrine, where the 'war-fighting ethos' has traditionally taken centre-stage (Milton, 2001: 41-44).

\footnotetext{
9 'British Defence Doctrine', 2008, pt. 201. See also: 'Delivering Security in a Changing World', 2003, pt.4.9 and 'Campaigning', JDP 01, Second Edition, MoD, 2008, pt.120;pt.125.

10 On the Comprehensive Approach see: 'Campaigning', 2008, pts.237-8 and The Comprehensive Approach', Joint Discussion Note, 4/05, 2006, pt.112.

11 See 'Incorporating and Extending the UK Military Effects-Based Approach Joint Doctrine', 7/06, Development Concepts and Doctrine Centre, Shrivenham, September 2006.

12 On Mission Command see 'British Defence Doctrine', 2008, pt. 508.

13 'British Defence Doctrine, 2008, pt.511.

14 It is, however, important to note the arguments of Owen (2008: 67), who posits that manoeuvre and attrition should be viewed as complementary.

15 'British Defence Doctrine', 2008, pt.521.

16 'British Defence Doctrine', 2008, pts.205-25 and 'Network Enabled Capability', p.3.

17 'British Defence Doctrine', 2008, pt.403e.

18 'FLOC', 2008, pt.120.

19 'The Significance of Culture to the Military', 2009, pt.5-1, Annex 5A.
} 
In summary, British defence reform has been strongly informed by US transformation and the principles of jointness, NCW and EBO. NEC and EBAO are, however, more limited in ambition than their US counterparts. While the British military retains the capability to undertake $\mathrm{MCO}$, it is more focused on the challenge of irregular conflict of rapidly-varying intensity. The 'human element' is also central to NEC. ${ }^{20}$ Furthermore, NEC and EBAO shun the 'longscrewdriver' approach to command and control in favour of the flexibility of Mission Command and are embedded within the principle of Manoeuvre Warfare and the Comprehensive Approach. ${ }^{21}$ Consequently, EBAO places a stronger emphasis on the role of non-kinetic effects than EBO.22 Rather than leading to a dramatic dissipation of EBAO, the decline of EBO in the US has, therefore, reinforced British observations EBO's weaknesses. The concept of EffectsBased Thinking prevails, that shuns the more 'deterministic' aspects of EBAO and reflects EBAO's utility in targeting 'closed systems' such as infrastructure. The language of effects has also been retained to describe to 'encourage users think about the effect they and their partners in a comprehensive approach to campaigning wish to achieve'. ${ }^{23}$

\section{A Stalling Defence Reform: Growing Stagnation in Capability Procurement and Force Postures}

There has been growing criticism of the 'balanced forces' approach that attempts to meet the challenges of 'Stabilisation/COIN' while retaining the capacity to conduct MCO and of the lack of definition on the precise implications of recent operational experiences for capabilities and force postures over the medium to long-term. There is an urgent need to rebalance capabilities to cope with 'Stabilisation/COIN' situations by increasing investment in strategic air-lift, medium- and heavy-lift transport helicopters and command, control, communications, computer, intelligence, surveillance and reconnaissance capabilities (C4ISR). The UK also faces overstretch in manpower-intensive COIN/Stabilisation, having significantly reduced infantry forces since 1990. Crucially, the 2003/04 DWPs were released before the requirement for a large-scale, long-term presence in Iraq and Afghanistan, which placed strain on the 2003/04 DWPs' planning assumptions (Cornish and Dorman, 2009a: 253).

Some initial rebalancing in favour of Stabilisation/COIN has been initiated. On 15 December 2009 Defence Secretary Bob Ainsworth (2009-10) announced an expansion of the Chinook helicopter fleet from 48 to 70 by 2012/13, funded by the closure of RAF Cottesmore Harrier Base, cuts to the Tornado and Nimrod fleets and a reduction of 7,500 civilian staff (IND, 2009). However, as former Chief of the Defence Staff, Sir Richard Dannatt (2008) argues, the possible loss of relative power through the non-renewal of Trident, or through the reduced power projection capability that would derive from scrapping CVF, makes these projects imperative. It is, therefore, likely that the SDSR will adopt a 'Seacorn' approach to capabilities such as anti-submarine warfare and the fighter jet fleet, retaining a basic capability, but investing heavily in the updating of doctrine, training and the skill-base of industry. ${ }^{24}$

Furthermore, the October 2009 Independent Review of Acquisition, conducted by Bernard Gray, highlights an 'overheated' capability acquisition process characterised by accelerating costs and timescales. ${ }^{25}$ The Report demonstrates that the key determinant of Britain's capacity to adapt to the changing security environment will rest not in the allocation of extra resources, but the structuring of military input to defence planning. The document points

\footnotetext{
20 'Network Enabled Capability', 2005, p.9. See also 'FLOC', pts.157;159.

21 'Campaigning', 2008, pts.237-8; 410c.

22 'Joint Air Operations: Interim Joint Warfare Publication 3-30,'JDCC, 2003, pt.506.

${ }^{23}$ EBO: Implications of Recent JFCOM Commander's Guidance', DG, DCDC, 24 September 2008'; Interviews, DCDC, Shrivenham, 18 November 2009; Interview, MoD, London, 20 November 2009. See also: 'Chapter 3 Influence: The Central Idea' in 'JDP 3-40, Security and Stabilisation', pt.301-2.

24 Interview, UKDA, Shrivenham, 18 November 2009.

25 'Review of Acquisition for the Secretary of State for Defence', 15 October 2009, p.6.
} 
to the need to urgently reform the capability acquisition process to allow civilian actors to exert greater control over the individual Services' procurement plans.

Since the 1998 SDR the institutional structures for capability acquisition have undergone several reforms, designed to ensure that projects reflect future possible conflict scenarios, whilst being responsive to contemporary operational requirements and to deliver projects on time and to budget. These reforms have, however, met with limited success in delivering capabilities on time, to budget, and in a prioritised manner. Gray's Report finds an 'overheated' procurement programme, concluding that the costs of programmes are on average $40 \%$ greater than planned and delivered $80 \%$ later than estimated. ${ }^{26}$ The Report notes the urgent requirement for a defence review to provide top-down guidance on the exact balance between MCO and 'Stabilisation/COIN' capabilities and demonstrates the negative impact of poor civilian control over acquisition that has led to overbidding and underestimations of cost. Problematic institutional structures are identified as the MoD Capability Sponsor (composed of Single-Service Officers) and the Defence Board (composed of Service Chiefs who are not subordinate to the Chief of Defence Staff and enjoy direct access to the Prime Minister). ${ }^{27}$ These organs, dominated by military input, are incapable of making a sober assessment of priorities in procurement. ${ }^{28}$ As a source within Defence Equipment and Support noted: 'The dominance of the Services in decision-making on procurement is highlyproblematic. It is questionable whether a military figure rooted in his/her Single-Service has the necessary neutrality to balance requirements with resources' ${ }^{29}$

Although there is a strong consensus about military 'best practice' over the short term, the nature of conflict scenarios over the medium-long term remains contested. ${ }^{30}$ Debates about future conflict scenarios are highly-politicised, exhibiting a mixture of 'campaign tribalism' and 'inter-service rivalry' (Cornish and Dorman, 2009b: 737-39), particularly at the senior levels of the Services, whose leaders wish to maximise long-term budget share. An MoD source noted: 'There is great desire for a rational prioritisation of capability investment at lower-levels of the Services but at the level of one-star officer and above career development depends upon how one delivers in defence of one's Service'. ${ }^{31}$

Consequently, the Army emphasises the long-term need to prepare for COIN/Stabilisation and exhibits a high-level of 'campaign tribalism' in favour of current operations in Afghanistan (Cornish and Dorman, 2009b: 737-39). The Navy draws attention to the potential for MCO and need for Carrier Strike Groups (BBC, 2009a), while the Air Force (despite recognising the short-term requirement to focus on ground-support, tactical air transport and helicopters) advocates investment in strike, attack and offensive-support aircraft (Edmunds, 2010: 384-85). ${ }^{32}$ Such debates highlight the increasingly urgent requirement for the 2010 SDSR to deliver explicit guidance on the medium to long-term balance to be struck between capabilities and force postures relevant for 'Stabilisation/COIN' and those capable of addressing other potential conflict scenarios.

\section{Competing Visions of Military Change: Neorealist and Cultural Approaches}

\footnotetext{
$26 \mathrm{lbid}, \mathrm{p} .16$

27 Ibid, p.30-1; interview, MoD, London, 20 November 2009.

28 Interview, DE\&S, MoD, Bristol, 16 November 2009.

29 Ibid.

30 The DCDC Global Strategic Trends Programme 2007-2036', DCDC, 2006 p. 68. See also: 'FLOC', 2008, pt.114, b.

31 Interviews, MoD, London, 19-20 November 2009.

$32 \mathrm{Ibid}$. It is, however, important to note that contestation also exists within the Services about their function and structure (Edmunds, 2010: 385).
} 
Cultural and Realist approaches dominate theoretical debate on the sources of military change. Cultural approaches emphasise the centrality of 'path dependency' and social construction in policy formation. Hence the literature on national 'strategic culture' posits that institutionally and societally-embedded norms 'predispose societies in general and political elites...toward certain ideas and policies' (Duffield, 1998: 27). This approach echoes the insights of sociological institutionalism: that institutions consist of 'symbol systems, cognitive scripts and moral templates that provide the "frames of meaning" guiding human action' (Hall and Taylor, 1996: 947). In their studies on German and French defence reform, Longhurst (2003) and Irondelle (2003) emphasise the role of 'path dependency'. The concept of 'path dependency' is rooted in historical institutionalism's assertion that institutions embody 'formal or informal procedures, routines, norms and conventions' and tool-kits of action which provide actors with ways of defining problems and 'logics of appropriate behaviour' (Hall and Taylor, 1996: 938).

Farrell (2005: 450) argues that norms of 'conventional warfare' exist not only at the national, but at the global level, 'which provide the basic template for military organisation'. These norms are embedded within transnational organisational fields and are disseminated through professional networks. Farrell (2005: 459-61) distinguishes between 'well-established' and 'poorly-established' norms (norms that are 'poorly defined, new or not widely accepted'). When faced with transnational norms that resonate with dominant domestic norms, norm transplantation/grafting will proceed uncontested (Farrell, 2001: 81). However, when faced with external challenge, the more established a norm is, the more likely it is that it will be 'bolstered' (the allocation of greater resources to the practices dictated by the norm at risk in order to prevent its failure) rather than 'stretched' (expanding the boundaries of what is deemed acceptable) (Farrell 2005: 459-61).

Neorealism also provides a compelling explanation for military change. As in the market place, where the 'invisible hand' of market competition determines the behaviour of firms, so the 'invisible hand' of anarchy rewards those who conform to its logic with an increase in power and security, and punishes those who do not, with decline, defeat and even destruction (Waltz, 1979: 89-93). Hence the anarchic logic of the international system drives change at the domestic level, leading to the adoption of new military methods (Posen, 1984). The systemic distribution of capabilities and consequent new security challenges, coupled with the necessity of survival in an uncertain, 'self-help' world, leads to three possible outcomes (which can be combined to varying degrees).

Firstly, the continuation of existing practices (policy inertia), whereby states fail to adapt to systemic imperatives and retain existing military objectives and instruments. Such stagnation will inevitably lead to a loss of power and influence. The second outcome is emulation, which constitutes the adoption of 'best practice': 'The possibility that conflict will be conducted by force leads to competition in the arts and instruments of force...contending states imitate the military innovations contrived by the country of greatest capability and ingenuity...competition produces a tendency towards sameness of the competitors...and so weapons of major contenders and even their strategies begin to look much the same' (Waltz, 1979: 127).

However, whereas Waltz (1979: 127) prioritises the distribution of capabilities and the balance of power as the drivers of military emulation, Joao Resende-Santos, (2007) highlights how emulation should be understood as a rational response to the powerful effects of structural uncertainty and the logic of competition. States seek to minimise the costs and risks consequent upon their self-help efforts by emulating proven effectiveness in conflict, rather than simply emulating the state of greatest capability, as this forms the quickest and most effective strategy that involves least risk (Resende-Santos, 2007: 51, 58-61).

The final outcome is innovation: 'the discovery of new knowledge, invention of new practices or their recombination in new forms' (Resende-Santos, 2007: 72). Innovation offers the promise of significant, though short-term, advantage over other states, due to the propensity of other great powers to mimic successful innovation. Innovation is, however, 
inherently risky due to the potentially catastrophic implications of poor strategic choices. International structure therefore acts as a selection mechanism on the basis of 'competitive effectiveness': the extent to which a state's defence policy will allow it to maximise its power and influence and ensure its survival, autonomy and prosperity (Resende-Santos, 2007: 63). The central criterion in determining the attractiveness of emulation is proven success in great power war (Resende-Santos, 2007: 81-2).

A state's propensity to innovation/emulation is determined by the interplay between three factors. The first factor is the resource-technological basis of a state. The greater the capabilities of a state, the lower the risk that is associated with failed innovation/emulation (Resende-Santos, 2007: 73). The second factor is the intensity of competition: as the security environment becomes more threatening, the 'safety margin' of risk decreases and all but the most innovation-capable primary states prioritise emulation (Resende-Santos, 2007: 85-9). The final factor is the presence of alliance options, which can provide an incentive to bandwagon on the power and innovations of other states in the international system (Resende-Santos, 2007: 88-92).

Cultural approaches posit that what at first appears 'radical', 'third-order' change to the objectives and instruments of British armed forces in the 1997/98 SDR actually resonated with deeply-embedded norms within the British military. In short, there was a strong degree of 'fit' between transnational and domestic norms (Farrell, 2001: 81). Convergence with systemic imperatives did not, for example, challenge the Army's embedded 'logic of appropriateness'. The Army's historical task in building and maintaining Empire developed a conception of the role of the army as fighting small wars outside Europe and a 'distaste for inactivity' (Thornton, 2003: 42-6) and had retained its 'colonial focus' throughout the 1970s/80s, allowing smooth adaptation to the SDR's expeditionary baseline (Thornton, 2003: 42-6).

Farrell (2009: 787) points to the role of 'realist' factors in determining the selective emulation of the core concepts and capabilities that underpin the RMA in the 2002 and 2004 White Papers: British resource constraints as a 'secondary power', the RMA's complexity, as well as operational experience alongside the US in the 2003 Gulf War that demonstrated the importance of 'old fashioned' virtues of speed, surprise and superior warfighting. Nevertheless, Farrell also argues that cultural factors were prominent variables determining the precise trajectory of reform. Scepticism of technology and the British system of Mission Command are identified as core features of the military's organisational culture and proved highly-resistant to the emerging transnational norms associated with EBO and NCW (Cassidy, 2004: 67-9; Farrell, 2008: 788). However, as the following section will demonstrate, rather than rooted in the subjectivity of culture, one could also view features such as Mission Command, the Manoeuvrist Approach, and the focus of NEC and EBAO on 'human factors' and non-kinetic effects as having been bolstered by objective lessons derived from observation of the RMA in practice and from British operational experiences.

\section{The Process of British Defence Reform: International Structure and Executive Autonomy}

Operational Experiences and the Emergence of NEC, EBAO and the Comprehensive Approach

As highlighted in the first section of the paper, it was not until the 2002 'New Chapter' and 2003/2004 DWPs that the implications of changes to the objectives of defence policy set out by the SDR were more clearly spelt out in terms of capability acquisition (Dorman, 2006: 152). This initial emphasis upon changes to policy objectives and military command structures in the SDR, followed by investment in procurement around NEC, reflects the insights of Neorealism. In the absence of an immediate threat to the territorial integrity of a state, policy makers in 'secondary' states err on the side of caution, follow the strategy of least risk and cost and 
commit themselves to significant defence procurement initiatives only when strategic imperatives and their associated 'best practice' in capability investment become clear and pressing (Dyson, 2008: 742, Hyde-Price, 2007: 32). The risks associated with an early emulation of the RMA were pertinently highlighted by Vice-Admiral Sir Jeremy Blackham, Deputy Chief of Defence Staff, Equipment Capability (1999-2002) in February 2000: 'If we use technology ineptly, fail to integrate projects properly within an overall programme, pick the wrong technology, fail to spot the weakness which an opponent could exploit, or simply do nothing, we leave ourselves at a potentially staggering disadvantage' (Blackham, 2000a: 34).

As Resende-Santos (2007: 88-92) notes, the presence of Alliance options also play an important role determining a state's propensity to military emulation or innovation. By the turn of the Century post-Cold War security challenges began to clarify and highlighted the continued importance of the US security guarantee to European security and the need for the European Great Powers to reinforce their utility as Alliance partners, underscoring the imperative of interoperability with US forces, necessitating emulation of the RMA. At the same time, the 1999 Kosovo Conflict (Operation Allied Force) demonstrated the dangers associated with overreliance on the US security guarantee and the need to establish an independent European capacity for military action within its geopolitical neighbourhood. Hence the UK would also need to invest in the networked capabilities that would allow it to lead medium-sized European higher-intensity operations. ${ }^{33}$

The Kosovo Conflict therefore played an important role in determining UK capability procurement. Operation Allied Force reinforced the changes instituted to defence policy objectives and command structures by the SDR and highlighted several networking and battlefield digitisation capabilities in need of acquisition to enhance jointness, to ensure the capacity to strike targets at speed and to allow the UK to remain a credible Alliance partner (Blackham, 2000a; 2000b; Dorman, 2006: 156). ${ }^{34} \mathrm{C} 2$ (Command and Control) capabilities were identified as in critical need of investment, having been proved lacking in the transfer of realtime information from ISR (Intelligence, Surveillance and Reconnaissance) assets, which had also been identified as deficient. Furthermore, information operations and strategic airlift were distinguished as requiring urgent development. ${ }^{35}$ The initial stages of the Afghanistan conflict also underscored the imperative of emulating core features of the RMA to ensure that the interoperability gap, particularly in C2, did not widen (Day, 2002: 38-43). ${ }^{36}$

At the same time, British conceptual development during the late 1990s, based upon the experiences of a growing number of crisis-management operations pointed to the need to invest in capabilities, training and doctrine enabling the military to achieve a wide-range of operational effects and coordinate its activities with other agencies and actors. ${ }^{37}$ During the early-mid 1990s British military doctrine made a sharp distinction between war, peacekeeping, peace-enforcement and COIN (Frantzen, 2005: 106). 'Wider Peacekeeping' (1994) emphasised impartiality and consent and failed to account for the lessons UNPROFOR (199295) imparted about the need for a more active military role in peace-enforcement. The document was quickly replaced by 'Joint Warfare Publication 3-50' that envisioned a more 'robust' role for Land Forces (Rollins, 2006: 88). The 1998 British Defence Doctrine formed an important watershed in thinking on expeditionary crisis-management operations (Cassidy, 2004: 185-199; Frantzen, 2005: 108; Kiszely, 1998: 39). The document pointed to the 'continuum of conflict' (the tendency of operations to vary quickly in intensity) and the difficulty

\footnotetext{
33 See: 'Future Capabilities, Factsheet 1: The Policy Baseline: Why We Need to Change', MoD, 2004 and 'Operations in Iraq: Lessons for the Future', 2003, pts.7.7-7.8.

34 See Geoff Hoon, House of Commons Debate, 11 December 2003, Hansard vol. 415, p.1209, Chapter 6, 'Key

Defence Capability Issues and Joint Lessons' in 'Kosovo: Lessons from the Crisis', 2000.

35 See 'Kosovo: Lessons from the Crisis', Chapter 6.

36 Interviews, DCDC Shrivenham, 18 November 2009; MoD, London, 20 November 2009.

37 'The Comprehensive Approach', 2006.
} 
of making sharp distinctions between peacekeeping and high-intensity conflict (Frantzen, 2005: 108).

Hence, by the early-mid 2000s the imperative of constructing a balanced, flexible force capable not only of $\mathrm{MCO}$, of undertaking 'Stabilisation/COIN', began to gain wider currency within the military. ${ }^{38}$ As Brigadier Melvin (2002: 42), Director of Land Warfare, argued in June 2002: 'British Land Forces should be prepared to conduct conventional warfighting, counterterrorism, and to win over the population simultaneously...Many of these are missions that human beings rather than technology are good at'. Consequently, even at the apex of US 'technological determinism', British thinking on networking focused as much on the role of hightechnology assets in enhancing 'Stabilisation/COIN' as on MCO (Burridge, 2003: 23). ${ }^{39}$

In short, the British experiences of full-spectrum operations during the 1990s had taken firm root by Afghanistan and Iraq. Consequently, although initial Effects-Based Thinking within the UK Joint Doctrine and Concepts Centre (JDCC) dovetailed with US EBO (Farrell: 2008: 791-2) it was more the 'best practice' demonstrated by operational experiences, than a culturally-embedded scepticism of technology that fostered resistance to a full-blown emulation of EBO. ${ }^{40}$ Bosnia, Kosovo, Sierra Leone, Iraq and Afghanistan also imparted the centrality of harmonising the collaboration of international organisations, the media, NGOs and Other Governmental Departments at the tactical, operational and strategic levels. ${ }^{41}$ EBAO has, therefore, developed with a stronger focus on the delivery of non-kinetic effects than EBO and has been firmly rooted within the Comprehensive Approach (Farrell, 2008: 795; Farrell and Gordon, 2009: 23-24). ${ }^{42}$ For these reasons the decline of EBO in the US has not involved a great conceptual leap, as British EBAO had already recognised many of EBO's pitfalls.

Rather than rooted in the subjectivity of culture, the principles of Mission Command and the Manoeuvrist Approach have also been bolstered by the lessons of operational experiences. The origins of Mission Command lie in Prussian military thought and the concept forms a key element of the British Manoeuvrist Approach. As Danchev (1998: 33-35) and Kiszely (1998) demonstrate, the core features of the Manoeuvrist Approach can be traced back to Sun Tzu, but also to the British theorist JFC Fuller (1928), and the 'indirect approach' of Basil Liddell Hart (1929). It was not, however, until the mid-1970s that Manoeuvre Theory was revised (Kiszely, 1999: 37) and the principle of Manoeuvre Warfare and its associated concept of Mission Command was only formally adopted in place of Montgomery's 'Set-Piece Battle' by the British military in 1987 (Kiszely, 1999). This relatively recent adoption of the Manoeuvrist Approach by the British casts some doubt on the depth of the concept's cultural 'roots' (Melvin, 2002: 39; Storr, 2003: 119-21).43

The British 'lessons-learned' process on command and control has been influenced not so much by culture, as by observation of US operations, notably the 2003 Iraq Conflict, which raised concerns about the potential of hierarchical command and control to undermine tempo and surprise (McColl, 2004: 52-3). This lack of attention to 'human factors' in NCW and EBO was, of course, confirmed by FM 3-24 in December 2006. Observation of the RMA has been supplemented by British operations, before and after the SDR. Operations in Bosnia, demonstrated the applicability of the Manoeuvrist Approach to peacekeeping at the operational and tactical levels (Kiszely, 1998: 39). Kosovo, Sierra Leone (2000) and Operation Telic also

\footnotetext{
38 Interviews, MoD, London, 19-20 November 2009.

39 Interviews, DCDC Shrivenham, 18 November 2009; MoD, 19-20 November 2009.

40 Interviews, DCDC, Shrivenham, 18 November 2009.

41 'The Comprehensive Approach', 2006, pt.102.

42 Farrell (2009: 24) notes that 'the UK military has made significant advances in terms of enhancing its capabilities and approaches to Counterinsurgency, and of working with civilian partners to stabilise and develop Helmand'. However it is important to note that the implementation of the Comprehensive Approach in Afghanistan has also been associated with significant problems (Grey, 2009; King, 2010: 311-14).

43 On contestation within the British military concerning Manoeuvrist Approach's utility, see Owen (2008: 62-7).
} 
illustrated the importance of the balance 'between direction and delegation' provided by Mission Command (Dorman, 2006: 156-57; Melvin, 2002: 40; Storr, 2003: 123). 44 Consequently, NEC and EBAO have been firmly-embedded within the Manoeuvrist Approach and its associated concept of Mission Command. As Major General Bailey (2004: 50) notes: 'On the modern battlefield where friendly, enemy and neutral elements intermingle, where the terrain, often urban, is complex, and where intentions become increasingly difficult to decipher, it will be, more than ever, the commander on the ground who will have the best feel for the truth.' The objective utility of the principles of Mission Command/Manoeuvre Warfare is further illustrated by the convergence of France and Germany around these principles during the postCold War era and the recognition within the US military of the need to adopt the principles of Mission Command in Stabilisation/COIN (Dyson, 2010: 146-47).45

In summary, rather than the interaction between domestic norms and global norms of conventional warfare, the selective emulation of US EBO and NCW that emphasises the centrality of 'human factors', flexibility in command and control and the importance of a Comprehensive Approach is primarily a result of British operational experience and conformity to 'best practice'. While a socialisation process is underway, it is not driven by transnational norms of conventional warfare, but by the powerful forces of uncertainty and competition. The imperative of determining the lessons of operational experiences and of assessing others' experiences with the RMA as objectively as possible formed a powerful mechanism spurring dynamism at the operational level. The potentially disastrous consequences of drawing erroneous lessons from ongoing conflicts acts as a powerful incentive to the military to attempt to strip doctrinal and conceptual development from subjectivity. This dynamism is, however, not a fully automatic process. As the following section will demonstrate, the role of the civilian leadership in structuring military input into defence planning has also been important in ensuring adherence to the dictates of operational experience and 'best practice'.

\section{Providing 'Institutional Protection’ for Operational Adaptability}

The operational dynamism of the British military has been facilitated by the institutional protection provided by the JDCC and UK Defence Academy (UKDA) for the principles of jointness and interoperability with alliance partners and capacity of these institutions to foster an environment of experimentation and critical thought on doctrine and Concept Development and Experimentation (CD\&E). ${ }^{46}$ The JDCC, established in the aftermath of the 1998 SDR, provided institutional protection for the 'transformation' process as networking gathered pace and the requirement for jointness became pressing (Cornish and Dorman, 2009a: 253; Frantzen, 2005: 107). ${ }^{47}$ The JDCC worked in partnership with the Single-Service Warfare Centres to enhance the objectivity of the 'lessons-identified' process by distancing doctrinal development and CD\&E from the bureaucratic politics of inter-service competition. In 2006 the JDCC was strengthened, becoming the DCDC and the central military authority on doctrinal and conceptual work.

Reforms have also been instigated to the UK 'lessons-identified' process following operations which have helped to develop a rigorous process of lesson-identification and followup on doctrine, training and capabilities at the operational level, particularly on jointness and interoperability. ${ }^{48}$ While doctrinal development during the Cold War was relatively static, the 1982 Falklands Campaign initiated the process of institutionalising lesson-identification within

\footnotetext{
44 Interviews, DCDC Shrivenham, 18 November 2009. On Mission Command and Operation Telic, see 'Chapter Three', 'Operations in Iraq...', 2003.

45 FM 3-24, pts.1-145-1.146.

46 Interviews, DCDC Shrivenham, 18 November, 2009; Interviews UK MoD, 19-20 November 2009.

$47 \mathrm{lbid}$.

$48 \mathrm{lbid}$.
} 
the Single-Service Warfare Directorates. ${ }^{49}$ It was not, however, until 1996 that lessonidentification received coordination through the establishment of the Permanent Joint Headquarters (PJHQ). The J7 Division of PJHQ, responsible for Joint Training has worked with the DCDC and Single-Service Warfare Centres to collate operational experiences and enhance joint warfare development. ${ }^{50}$ The PJHQ acts a 'service agnostic node' in lesson-identification and follow-up, determining which service will take the lead on implementing joint lessons. ${ }^{51}$ The DCDC, in partnership with the Single-Service Warfare Centres, heads up the interviewing of several levels of command following operations and distills and disseminates key joint lessons. ${ }^{52}$ The DCDC enjoys a good working relationship with the Warfare Centres which have, overall, been cooperative in developing a strong culture of jointness. ${ }^{53}$ The DCDC is also active in identifying and communicating lessons-learned with Allies through NATO and enjoys close bi-lateral relationships with JFCOM and US Single-Services. ${ }^{54}$ The lessons of operational experience quickly find their way into pre-deployment training, as Officers and Commanders who have had recent experience of deployment are closely involved in the development and delivery of training. ${ }^{55}$

Despite the PJHQ and DCDC lead role and implementation of an IT system in support of the lessons-identified process, the system of lesson-identification has received criticism for its follow-up. The Single-Services retain authority in identifying and following-up the lessons of operations which are not perceived by PJHQ/DCDC as having implications for jointness. Although the lessons-identified processes of the Services are viewed by the DCDC and other actors within the MoD as competent, the Services retain the capacity to erect a 'firewall' hindering the ability to determine the extent of follow-up. ${ }^{56}$ Hence there is a requirement for more neutral, centralised management of follow-up for Single-Services issues.

Furthermore, in 1995 the Directorate of Operational Capability (DOC) was established under former Defence Secretary Michael Portillo (1995-7). DOC conducts audits of the operational capabilities set by the Defence Programme Directory (an internal MoD document matching Defence Planning Assumptions to Force Structures and Capabilities) and gathers and exposes operational lessons. DOC reports directly to the Ministerial level, and is meant to act an extra filter to sift-out organisational politics. ${ }^{57}$ The Vice-Chief of Defence Staff takes responsibility for ensuring that problems identified are followed-up and implemented and must answer to the Defence Secretary. DOC's capacity to translate operational lessons into changes to force posture/capabilities is, however, constrained by the direction to force postures delivered within the 2003/04 DWPs, which the Services can invoke to justify the status quo. ${ }^{58}$

The UK has also implemented the Urgent Operational Requirements (UOR) scheme coordinated by PJHQ and the MoD. Since the inception of operations in Iraq and Afghanistan the scheme has involved an outlay of $£ 3.6$ billion (MoD, 2009). ${ }^{59}$ Financed by contingency funding from the Treasury, UORs must be fielded with 18 months of a request's ratification. The scheme is self-policing by the MoD and PJHQ with broad oversight from the Treasury; a system that functions well, as should the MoD UORs to request non-urgent equipment, it would threaten a valuable stream of revenue. ${ }^{60}$ It has, however, been more difficult to push through

\footnotetext{
49 Ibid.

50 Interview, MoD, London, 19 November 2009.

51 Interviews, MoD, London, 19-20 November 2009.

52 Interviews, DCDC, Shrivenham, 18 November 2009.

53 Interviews, DCDC, Shrivenham, 18 November 2009; MoD, London, 19-20 November 2009.

54 Interviews, DCDC, Shrivenham, 18 November, 2009.

55 Interviews, DCDC, Shrivenham, 18 November 2009; Interview MoD, 19 November 2009.

56 Interviews, DCDC, Shrivenham, 18 November 2009; MoD 19-20 November 2009.

57 Interviews, MoD, London, 19-20 November 2009.

$58 \mathrm{lbid}$.

59 Interview, MoD, London, 20 November 2009.

60 Interviews, MoD, London, 19-20 November 2009.
} 
changes to the formal equipment programme following the identification of UORs with mediumlong term implications (for reasons explored below). ${ }^{61}$

In summary, despite some problems, the set of institutional reforms undertaken since the mid-late 1990s has been largely successful in promoting jointness and interoperability and in the identification of and conformity to 'best practice' at the operational level.

\section{Neoclassical Realism and the Temporal Management of Reform at the Strategic Level}

As outlined earlier in the paper, the 'bottom-up' dissemination of post-Cold War lessonslearned into far-reaching changes to force postures and capability investment has been hampered by the impact of organisational politics at the higher-levels of the Services. ${ }^{62}$ Yet, as this section will demonstrate, it is not organisational politics that is the key variable in determining 'strategic drift'. Causality lies in the electoral cycle that has incentivised the temporal management of defence reform by the core executive since the mid-2000s. This has hindered dynamism in the strategic direction of British defence policy and defence capability procurement during the final term of the Labour Government (2005-10) and has reduced the ability of the core executive to make crucially-needed changes to the procurement process.

Hence, while Neorealism provides a compelling framework to conceptualise the selective emulation of the RMA and dynamism at the operational level, it emerges as a more limited tool in understanding the precise timing of reform, particularly at the strategic level. Neorealism posits that executive decision-makers enjoy a high-level of autonomy in translating threats from the international security environment into changes to military doctrine and structures and in overcoming domestic opposition and organisational politics. The theory argues that the ability of policy-makers to drive change is particularly strong as the level of external threat increases and models of military best practice become clear, due to the potentially catastrophic implications of the loss of relative power that can result from faulty strategic choices (Posen, 1984). Neorealism is, therefore, unable to fully explain the process of British defence reform, as despite increasing pressure from the international security environment (notably the clear need to reprioritise capabilities and force structures for ongoing operations in Afghanistan and Iraq since 2006), reform has been subject to temporal management during the last Parliament (Cornish and Dorman, 2010: 409).

Cornish and Dorman (2009a; 2009b; 2010) highlight the myriad of problems facing British policy following the deployments in Afghanistan and Iraq and note the difficult choices decision-makers will encounter in the forthcoming SDSR in the context of economic crisis. However, they deliver no overarching explanation of the process and outcome of UK defence reform; of the pattern of operational dynamism and strategic inertia identified in this paper. Neoclassical Realism provides a compelling theoretical framework with which to conceptualise these phenomena. In accordance with the core premises of Neorealism, the theory posits that states seek will, over the long-run, seek to maximise international influence according to their relative material power. Yet the theory also shares Classical Realism's concern with the impact of domestic-level variables. It argues that 'state power' (the impact of the strength of a country's state apparatus and its relations to the surrounding society upon ability of the state to mobilise and extract resources from society) is highly-varied and forms the central intervening unit-level variable explaining short to medium-term temporal divergence with the dictates of international structure (Lobell et al 2009: 25).

There is a substantial and growing literature on Neoclassical Realism that is characterised by contestation over the unit-level variables which should be accorded priority in

\footnotetext{
61 Interview, MoD, London, 20 November 2009.

62 Interviews, MoD, London, 19-20 November 2009.
} 
determining 'state power'. Neoclassical Realist scholars such as Schweller (2004: 169); Snyder (1991); Taliaferro (2006); Van Evera (1999) and Zakaria (1998: 38) integrate a wide array of variables which impact upon 'state power', including ideology and culture. This section highlights the central intervening role played by domestic material power relations in determining the timing of British convergence with the dictates of 'best practice'. It argues that the level of autonomy afforded to the political executive by the electoral cycle (executive autonomy) forms the key variable in explaining the inability of the Labour Government to effectively structure military input to defence planning on issues of defence capabilities and force postures.

In accordance with Neorealism, it is important to note the impact of the lack of clarity about 'best practice' in capability investment on the inability of civilian leaders to provide compelling top-down guidance on procurement until the early $21^{\text {st }}$ Century. This factor must also be taken into account when explaining the disjuncture between financial planning and defence acquisition following the 1997/98 SDR (Cornish and Dorman, 2010: 405) and in understanding why the SDR was 'less forward-thinking in its assessment of the technologybased RMA' (Cornish and Dorman, 2009a: 252). In 1997/98 a significant degree of uncertainty persisted about the implications of the RMA and unipolarity, making it difficult to forsee the consequences for capability procurement and the defence budget.

Nevertheless, the root cause of the current strategic drift in UK defence policy lies not in the gradual process of 'strategic learning', but in the constraints of decreased executive autonomy. It is broadly recognised within the MoD that an SDR was required in 2006/07 as the imperative of striking a more appropriate balance between requirements in Afghanistan//raq and potential future conflict scenarios became apparent, and the concepts and necessary C4ISR capabilities associated with the UK's selective emulation of the RMA had clarified.63 However, the core executive's ability to undertake far-reaching reforms to ameliorate the effect of campaign tribalism and organisational politics between the Single-Services on capability procurement and force postures grew increasingly limited from 2007. At this point, the Government, with declining popularity and a General Election on the horizon, became acutely sensitive to the potential for 'bad news' in terms of jobs lost within the UK defence industry (that supplies $10 \%$ of UK manufacturing jobs and is $75 \%$ dependent on MoD expenditure) (BBC, 2009b). ${ }^{64}$ Labour was also highly-sensitive to the potential electoral fall-out of widespread base closures which would follow significant changes in force postures. ${ }^{65}$

The impact of the electoral cycle dissuaded the core executive from conducting a defence review in 2006/07, precisely when it became apparent that rebalancing of capability investment and force posture to cope with the challenges of COIN and large-scale, sustained campaigning in two theaters of operation was required. ${ }^{66} \mathrm{~A}$ review could only have been launched immediately following Labour's election victory in 2005. The implementation of a review completed later than the first 12-18 months of the new Parliament would have had a negative impact on Labour's performance at the following election. Consequently, Ainsworth only officially recognised the need for a new defence review in July 2009 and the Cabinet Office instructed Ainsworth to 'keep defence as quiet as possible before the general election' in recognition of difficulties associated with implementing a defence review (Cornish and Dorman, 2010: 401).67 An earlier review that developed broad cross-party consensus on the strategic direction of British defence policy and the implications for capabilties and force structures would

\footnotetext{
63 Interviews, DCDC and Joint Services Command and Staff College, Shrivenham, 18 November 2009; interviews, MoD, London, 19-20 November 2009.

64 Ibid.

65 Interviews, Defence Ministry, London, 19-20 November 2009.

$66 \mathrm{lbid}$.

67 lbid.
} 
have had the effect of ameliorating both inter-Service rivalry and 'campaign tribalism' by compelling the Single-Services to undertake far-reaching reform.

UK defence policy has, therefore, been subject to an excessively long phase of 'policy failure/inertia' (Cornish and Dorman, 2010: 400-03). This situation contrasts markedly with the high executive autonomy enjoyed by Labour following the 1997 General Election, in the form of its large Parliamentary majority, facilitating the implementation of the far-reaching changes of the 1997/98 SDR. The extended stage of policy inertia in the UK also mirrors the more persistent problems encountered by the German core executive in implementing defence reform due to frequent Laender elections (Dyson, 2008: 749-58). As a senior source noted: 'The current drift in UK defence policy is a consequence of the electoral cycle: no government would be in a position to implement a resource-driven SDR process at any point other than the first two years of a new Parliament'. ${ }^{68}$ However, this narrow executive autonomy may persist in the new Parliament, as the internal politics of the new Conservative-Liberal coalition government could well impact on the core executive's willingness to push through unpopular base closures and major changes to defence acquisition.

\section{The Way Forward: Preparing Institutional Protection for the SDSR}

The January 2010 Green Paper outlined the Labour Government's intention to conduct a defence review every four/five years and provide regular 'top-down' guidance on the strategic direction of reform. This proposal also found support amongst the Conservatives. Cornish and Dorman (2010: 404-06) are, however, highly-critical of the process of 'policy formulation' associated with previous defence reviews and identify the March 2008 National Security Strategy as a more appropriate model of 'grand, strategic cross-governmental guidance' (Cornish and Dorman, 2009b: 741). Yet the 1997/98 SDR was not without its merits.

The 1997/98 SDR, as Mclnnes (1998: 830) notes, involved close coordination between the MoD and Foreign Office and a 'clear attempt to devise a process whereby foreign policy principles would lead to military missions and force postures'. The SDR was, therefore, able to build strong cross-party consensus on defence that aligned defence with foreign policy and reduced the Treasury's impact on the SDR's outcome (Mclnnes, 1998: 844). ${ }^{69}$ As Cornish and Dorman (2010: 409) highlight, the forthcoming SDSR must also be driven by the 'clearest sense of foreign policy goals' and avoid being determined solely by 'affordability'. The final process of determining 'troops to task' in the 1997/98 SDR was, however, more dependent on internal MoD advice (McInnes, 1998: 833). In their examination of defence planning throughout history Imlay and Toft (2006: 250) note that 'effective war planning requires as many inputs as possible'. However, this process should not exclude the military. Having consulted widely on the broad strategic direction of the 1997/98 SDR and imbued the key changes in task with gravitas, it made sense to allow military planners greater room to determine the more specialist issues of 'troops-to-task'. In summary, while attaining broad direction from a revised National Security Strategy is a sensible approach, the SDSR would do well to achieve the 1997/98 SDR's balance between military and civilian input, particularly on the strategic vision underpinning UK defence policy.

Furthermore, reforms are planned to strengthen the capacity of the MoD's Directorate General (DG) Strategy to deliver the goals identified by the SDSR and avoid 'policy misimplementation' (Cornish and Dorman, 2010: 407-08). DG Strategy is responsible for strategic assessment and fleshing-out force posture baselines and works closely with the Defence Intelligence Staff to develop the Strategic Assessment; a classified document that

\footnotetext{
68 Ibid.

69 The 2002 New Chapter and 2003/04 DWPs, which delivered a more evolutionary approach to defence policy, involved a greater reliance on internal expertise and significant input from the MoD's Policy Planning Directorate (Cornish and Dorman, 2009: 253).
} 
outlines key areas of insecurity over a $15-20$ year period..$^{70}$ The DCDC has also become an increasingly important actor providing input to the future conflict scenarios developed by DG Strategy, to the point that the DCDC is referred to within the MoD as the 'Ministry's Fourth Floor'. 71

The DG Strategy is particularly 'civil servant-heavy' in order to attempt to insulate Strategy from Single-Service agendas. ${ }^{72}$ However, the DG's capacity to overcome the 'status quo' on delivering policy into programme has been hampered by yearly planning rounds which provide 'post-facto justifications for existing force structures' and by the Defence Board's ability to block major change, leaving DG Strategy constantly playing 'catch-up'. ${ }^{73}$ Consequently the yearly planning rounds will be replaced a new process of policy implementation following the SDSR. ${ }^{74}$ Defence Strategic Direction (DSD) will supercede Defence Strategic Guidance and form a more concise, longer-term (15-20 year) resource-informed vision of defence priorities. The DSD will be accompanied by a Defence Plan outlining how the DSD will be realised over the near-term (5 years), divided into a set of 10 sub-strategies for delivery. ${ }^{75}$

Finally, Gray's Report, although highly-embarrassing for Labour, has imbued potential acquisition reforms impetus, which, if enacted will facilitate the implementation of a resourceled SDR that matches financial constraints and strategy. ${ }^{76}$ The key recommendations of the Review were broadly accepted by Ainsworth. ${ }^{77}$ Gray's proposals also found support within the Defence Acquisition Reform Project Team (AOF, 2009) and a number of these proposals have been taken up in the February 2010 Defence Strategy for Acquisition Reform. ${ }^{78}$

\section{Conclusions: The Implications for Future Research}

Defence policy during the Labour Government has been caught between the push and shove of 'international structure' and the constraints of narrowing executive autonomy. These findings challenge the insights of cultural approaches to the sources of military change: the literatures on transnational norms, path dependency, organisational and strategic culture. The paper also contributes to the growing literature on Neoclassical Realism. The focus on executive autonomy and domestic material power relations adds greater parsimony to a theoretical approach that is characterised by contestation over the domestic-level variables which impact upon 'state power' (Lobell et al, 2009: 297-98). Nevertheless, empirical research on the precise extent to which other variables, such as ideology and nationalism, emerge as constraints or tools for policy leaders in the generation of military power would add greater nuance to a Neoclassical Realist analysis of British defence policy.

Furthermore, the study draws attention to the need for a closer focus on civil-military relations in defence planning and on the precise balance between the 'top down' (civilian-led) and 'bottom-up' (military-led) dynamics of defence reform. The competitive nature of the international system provides strong incentives to draw the correct conclusions from military operations and observations of others' experiences. However, there is also room for individual policy leadership in designing effective institutional protection for operational dynamism and for broader strategic-level defence planning (Rynning, 2001/02: 91-2). Further empirical and theoretical research is required on the role of policy leadership traits and skills both within the

\footnotetext{
70 Interviews, MoD, London, 20 November 2009.

71 Interviews, MoD, London, 19-20 November 2009.

72 lbid.

73 Ibid.

74 lbid.

$75 \mathrm{lbid}$.

76 Interview, DE\&S, Bristol, 16 November 2009; Interviews, MoD, London, 19-20 November 2009.

77 'Ministerial Statement Independent Review of Defence Acquisition', 15 October 2009.

78 'The Defence Strategy for Acquisition Reform,' Stationary Office, 10 February 2010.
} 
civil service and the core executive, as part of a broader examination of the management of internal structures of delegation and oversight within the Defence Ministry (Dyson, 2007; Stulberg, 2007: 35). Such 'organisational capablities'79 are an important attribute in the effective generation of military power and the maximisation of international power and influence. While Cornish and Dorman (2009a; 2009b and 2010) touch upon the issue of deficits in UK strategic-level defence planning, the literature on post-Cold War defence reform, not only on Britain, but also on the other European Great Powers is remarkably quiet on this timely subject. Given the tight economic constraints to which defence budgets will be subject over coming years, it will be more crucial than ever that civilian decision-makers are able to filter out the negative impact of inter-service rivalry and campaign tribalism and ensure the effective integration of actors from civil-society in determining doctrine, CD\&E, questions of force postures and capability investment. Further comparative work in this area is urgently required.

\section{Bibliography}

AOF (2009), http://www.aof.mod.uk/aofcontent/downloads/gray/review_of_acqn.pdf, date accessed 19 October 2009.

BBC (2009a), http://news.bbc.co.uk/2/hi/uk_news/8081969.stm, date accessed 3 June 2009.

BBC (2009b), http://news.bbc.co.uk/2/hi/uk_news/8230910.stm, date accessed 31 May 2010.

Bailey, J. (2004), 'The UK's Approach to Command: A Doctrinal Perspective', Doctrine (5), pp.47-50.

Benbow, T. (2009), 'Irresistible Force or Immovable Object? The "Revolution in Military Affairs" and Asymmetric Warfare', Defense and Security Analysis 25 (1), pp.21-36.

Blackham, J. (2000a), 'Handling the Digitised Battlespace', RUSI Journal 145 (1), pp.33-37.

Blackham, J. (2000b), 'The Apotheosis of $21^{\text {st }}$ Century Warfare', RUSI Journal 145 (6), pp.648.

Boyce, M. (2003), 'Achieving Effect: Annual Chief of Defence Staff Lecture', The RUSI Journal 148 (1), pp.30-7.

Burridge, B. (2003), 'UAVs and the Dawn of Post-Modern Warfare', RUSI Journal 148 (5), pp.18-23.

Cassidy, R. (2004), Peacekeeping in The Abyss (Westpoint: Praeger).

Cornish, P. and Dorman, A. (2009a), 'Blair's Wars and Brown's Budgets', International Affairs 85 (2), pp.247-61.

Cornish, P. and Dorman, A. (2009b), 'National Defence in the Age of Austerity', International Affairs 85 (4), pp.733-53.

Cornish, P. and Dorman, A. (2010), 'Breaking the Mould: The UK SDR 2010', International Affairs 86 (2):395-410.

Dahl, E. (2002), 'Network Centric Warfare and the Death of Operational Art', Defence Studies 2, (1) pp.1-24.

Danchev, A. (1998), 'Liddell Hart and Manoeuvre', RUSI Journal 143 (6), pp.33-5.

Dannatt, R. (2008), 'The Future Land Environment', RUSI Journal 153 (4), pp.56-61.

Day, J. (2002), 'After Afghanistan: The Role of Air Power', RUSI Journal 147 (6), pp.38-43.

Dorman, A. (2006), 'Britain and Defence Transformation: A Model of Success or a Warning of Its Dangers?', Defence Studies 6 (2), pp.150-68.

Dorman, A. (2007), 'Britain and Its Armed Forces Today', The Political Quarterly 78 (2), pp.32027.

Duffield, J. (1998), World Power Forsaken (Stanford: Stanford University Press).

Dyson, T. (2007), The Politics of German Defence and Security (New York: Berghahn).

79 The concept of organizational capability is drawn from the literature on strategic management and is defined by Kaplan and Norton (2004: 52) as the 'capacity of the organization to mobilise and sustain the process of change required to execute strategy'. 
Dyson, T. (2008), 'Convergence and Divergence in post-Cold War British, French and German Military Reforms', Security Studies 17 (4), pp.725-74.

Dyson, T. (2010), Neoclassical Realism and Defence Reform in post-Cold War Europe (Basingstoke: Palgrave).

Edmunds, T. (2010), 'The Defence Dilemma in Britain', International Affairs 86 (2), pp.377-84.

Farrell, T. (2001), 'Transnational Norms and Military Development', European Journal of International Relations 7 (1), pp.63-102.

Farrell, T. (2005), 'World Culture and Military Power', Security Studies 14 (3), pp.448-88.

Farrell, T. (2008), 'The Dynamics of British Military Transformation', International Affairs 84 (4), pp.777-807.

Farrell, T. and Gordon, S. (2009), 'COIN Machine', RUSI Journal 154 (3), pp.18-25.

Frank, A. (2004), 'Get Real: Transformation and Targeting', Defence Studies 4 (1), pp.64-86.

Frantzen, H. (2005), NATO and Peace Support Operations 1991-99: Policies and Doctrines (Abingdon: Routledge).

Fuller, J. (1928), On Future Warfare (London: Sifton Praed).

Hall, P. and Taylor, R. (1996) 'Political Science and the Three New Institutionalisms', Political Studies 44 (5), pp.936-57.

Ho, J. (2005), 'The Dimensions of EBO', Defence Studies 5 (2), pp.169-87.

Hyde-Price, A. (2007), European Security in the 21st Century: The Challenge of Multipolarity (Abingdon: Routledge).

Imlay, T. and Toft, M. (2006) The Fog of Peace and War Planning (Abingdon: Routledge).

IND (2009), http://www.independent.co.uk/news/uk/home-news/navy-and-raf-pay-the-price-tofund-afghan-war-1841975.html, date accessed 31 May 2010.

Irondelle, B. 'Civil-Military Relations and the End of Conscription in France', Security Studies 12 (3), pp.157-87.

Kaplan, R. and Norton, D. (2004), 'Measuring the Strategic Readiness of Intangible Assets', Harvard Business Review 82 (2), pp.52-63.

King, A. (2005), 'Towards a Transnational Europe: The Case of the Armed Forces', European Journal of Social Theory 8 (3), pp.321-40.

King, A. (2010), 'Understanding the Helmand Campaign: British Military Operations in Afghanistan', International Affairs 86 (2), pp.311-332.

Kiszely, J. (1998), 'The Meaning of Manoeuvre', RUSI Journal 143 (6), pp.36-40.

Kiszely, J. (1999), 'Achieving High-Tempo New Challenges', RUSI Journal 144 (6), pp.47-53.

Kiszely, J. (2006), 'Learning About Counter-Insurgency', RUSI Journal 151 (6), pp.16-21.

Krepinevic, A. (2004), Transforming the Legions (Washington: Centre for Strategic and Budgetary Assessment, 2004).

Liddell Hart, B. (1929), The Decisive Wars of History (Bell and Sons: London).

Lobell, S. et al (2009), Neoclassical Realism, the State and Foreign Policy (Cambridge: CUP).

Longhurst, K. (2003) 'Why Aren't the Germans Debating the Draft? Path Dependency and the Persistence of Conscription', German Politics 12 (2), pp.147-65.

Mattis, J. (2008), 'Commander's Guidance for EBO', Joint Forces Quarterly 51 (4), pp.105-8.

Mandille, L-C. (2003), 'The British Battlefield Digitization', Doctrine (1), pp.50-5.

McColl, J. (2004), 'Adapting Command Hierarchies', RUSI Journal 149 (1), pp.52-5.

Mclnnes, C. (1998), 'Labour's Strategic Defence Review', International Affairs 74 (4), pp.82345.

Melvin, M. (2002), 'Continuity and Change: How British Army Doctrine is Evolving to Match the Balanced Force', RUSI Journal 147 (4), pp.38-44.

Milton, A. (2001) 'British Defence Doctrine and the British Approach to Operations', RUSI Journal 146 (6), pp.41-4.

Owen, W. (2008), 'The Manoeuvre Warfare Fraud', RUSI Journal 153 (4), pp.62-7. 
Posen, B. (1984) The Sources of Military Doctrine: France, Britain and Germany Between the Wars (Ithaca: Cornell University Press).

Posen, B. (2006) 'ESDP: Response to Unipolarity,' Security Studies 15 (2), pp.149-86.

Resende-Santos, J. (2007), Neorealism, The State and the Modern Mass Army (Cambridge: CUP).

Rollins, J. (2004), 'Command in Operations: The Lessons From the British Experience in Iraq', Doctrine (5), pp.59-62.

RUSI

(2009), http://www.rusi.org/go.php?structureID=S433AC69DF0216\&ref=C49F9BEE224FA0., date accessed 15 July 2009.

Rynning, S. (2001/02), 'Shaping Military Doctrine in France: Decision-Makers Between International Power and Domestic Interests', Security Studies 11 (2), pp.85-116.

Schweller, R. (2004), 'Unanswered Threats: A Neoclassical Realist Theory of Underbalancing', International Security 29 (2), pp. 159-201.

Snyder, J. (1991), The Myths of Empire: Domestic Politics and International Ambition (Ithaca: Cornell).

Storr, J. (2003), 'A Command Philosophy for the Information Age', Defence Studies 3 (3), pp.119-129.

Stulberg, A. et al (eds.) (2007), Managing Defense Transformation (Aldershot: Ashgate).

Taliaferro, J. (2006), 'State-Building for Future Wars: Neoclassical Realism and the ResourceExtractive State', Security Studies 15 (3), pp.464-95.

Thornton, R. (2003), 'A Welcome Revolution? The British Army and the Changes of the SDR', Defence Studies 3 (3), pp.38-62.

Van Evera, S. (1999) Causes of War: Power and the Roots of Conflict (Ithaca: Cornell). Zakaria, F. (1991) 'Realism and Domestic Politics', International Security 7 (1), pp.177-98.

Waltz, K. (1979), Theory of International Politics (Reading: Addison Wesley). 